\title{
Microbiological Concordance in the Management of Diabetic Foot Ulcer Infections with Osteomyelitis, on the Basis of Cultures of Different Specimens at a Diabetic Foot Center in China
}

This article was published in the following Dove Press journal:

Diabetes, Metabolic Syndrome and Obesity: Targets and Therapy

\author{
Xuemei $\mathrm{Li}^{1,2}$ \\ Qingfeng Cheng $\mathbb{1 D}^{3}$ \\ Zhipeng $\mathrm{Du}^{3}$ \\ Shenyin $\mathrm{Zhu}^{2}$ \\ Chao Cheng ${ }^{4}$
}

'Department of Pharmacy, Chongqing Health Center for Women and Children, Chongqing, People's Republic of China; ${ }^{2}$ Department of Pharmacy, First Affiliated Hospital of Chongqing Medical University, Chongqing, People's Republic of China;

${ }^{3}$ Department of Endocrinology, First Affiliated Hospital of Chongqing Medical University, Chongqing, People's Republic of China; ${ }^{4}$ Department of Critical Care Medicine, Xiangyang Central Hospital, Affiliated Hospital of Hubei University of Arts and Science, Hubei, People's Republic of China
Correspondence: Chao Cheng Department of Critical Care Medicine, Xiangyang Central Hospital, Affiliated Hospital of Hubei University of Arts and Science, No. 136, Jingzhou Street, Xiangcheng District, Hubei, 44I02I,

People's Republic of China

Tel +86238901 240I

$\mathrm{Fax}+8623$ 68811793

Email chengchaol Ic0@I63.com

Shenyin Zhu

Department of Pharmacy, First Affiliated Hospital of Chongqing Medical University, No. I, Yixueyuan Road, Yuzhong District, Chongqing, 400016, People's Republic of China

Tel +862389012401

$\mathrm{Fax}+862368811793$

Email zhushenyin0486@sina.com
Objective: This study aimed to assess the microbiological concordance between swab and soft tissue cultures, and corresponding bone specimen cultures from patients with diabetic foot osteomyelitis (DFO). We aimed to analyze the bone specimens' antimicrobial susceptibilities, and to improve clinical management of diabetic foot ulcer infections by using proper antibiotics.

Methods: The microbial culture results of ulcer swabs, and soft tissue and bone tissue specimens, and the antimicrobial susceptibility tests of bone specimens from patients with DFO were analyzed in a single diabetic foot center.

Results: A total of 60 patients with results from three specimens were included. Staphylococcus aureus was the most common bacterium isolated from the three specimens. The microbiological results for the three specimens were identical in 12 cases, the culture results from swabs and bone tissue specimens were identical in 14 cases, and the results from soft tissue and bone tissue were identical in 46 cases. The concordance of the results of pathogens isolated between soft tissue and bone specimen cultures was higher than that between the swab and bone cultures. Gram-positive bacteria were more sensitive to moxifloxacin, linezolid, and vancomycin, while Gram-negative bacteria were more sensitive to piperacillin/tazobactam, cefoperazone/sulbactam, and carbapenems.

Conclusion: Soft tissue culture results have more reliable microbiological concordance to identify DFO bacteria than swab culture results and targeted antibiotic therapy for DFO should be based on antimicrobial susceptibility testing in bone tissue specimen cultures.

Keywords: diabetic foot osteomyelitis, ulcer swabbing, microbiological concordance, antimicrobial susceptibility test, targeted antibiotic therapy

\section{Introduction}

Diabetic foot ulcers (DFUs) are one of the most common complications of diabetes, and infections occur in more than half of foot ulcers. ${ }^{1}$ These ulcers frequently become infected, thus, leading to diabetic foot osteomyelitis (DFO), and requiring health care, antimicrobial treatment, and lower extremity amputations. ${ }^{2}$ Often, DFU with osteomyelitis requires a multidisciplinary approach, owing to difficulties in clinical diagnosis and treatment. ${ }^{3-5}$ However, identifying the pathogens responsible is complicated by the presence of both pathogens and colonizers in most DFOs. Therefore, accurate pathogen diagnoses and targeted antibacterial therapy for DFOs 
are urgently needed, and are dependent on accurate specimen collection, cultivation, pathogen identification, and susceptibility testing. ${ }^{6}$ Current evidence supports the evaluation of bone specimens as the best reliable diagnostic technique for bone infections; this method provides reliable data on related pathogenic bacteria and antimicrobial susceptibility. ${ }^{7-12}$ Thus, the type of specimen collection may be crucial in identifying the true pathogens underlying DFOs. Three techniques can be used to obtain specimens for culture from DFOs: swab, tissue biopsy, and bone biopsy. Previous studies have suggested that bone biopsy is the gold standard culturing technique for DFOs, whereas swab cultures are the least reliable, because they have been reported to contain high numbers of colonizers and often lack the true pathogens pathogens. ${ }^{3,8,9,13-16}$ However, bone specimens cannot always be collected from DFOs because of concerns regarding infection spread, ischemia, or damaging adjacent structures. ${ }^{17}$ Therefore, swabs or soft tissue specimens are used instead of bone specimens for microbiological assays. Furthermore, swabs or soft tissue may be collected by any member of a health-care team, and swab or soft tissue specimens can be sent to a microbiology laboratory immediately if surgical debridement must be delayed. Therefore, the results from swab or soft tissue specimen cultures are commonly used for identifying pathogens and selecting antibiotics. However, previous research has suggested that swabs and soft tissue specimens do not provide an accurate picture of the organisms in the deep tissue and bone biopsy samples. ${ }^{8,13-16,18}$ In addition, the above studies have shown large disparities in the pathogenic bacteria cultured from swabs or soft tissue specimens versus bone tissue specimens. However, studies comparing the results of bone, swab, and soft tissue specimen cultures for patients with DFOs are lacking. In addition, $77.8 \%$ of patients with DFO display bacterial resistance to the initial empirical antibiotics administered. ${ }^{19}$ Therefore, the initial targeted antibiotic therapy is essential for the management of DFO.

In this study, we retrospectively investigated whether the bone tissue culture results of patients with DFOs were consistent with those of swabs and soft tissues, and we analyzed the distribution and susceptibility of pathogenic bacteria in bone tissue, with an aim to reexamine the reliability of swabs, soft tissue specimens, and bone tissue specimens, and to provide guidance for DFOs in patients with targeted antibacterial therapy. To our knowledge, this is the first study simultaneously comparing the microbiological concordance in the culture results of bone tissue, swabs, and soft tissues in patients with DFO.

\section{Patients and Methods Patients}

From May 2016 to December 2019, a total of 230 patients with DFO were admitted to the Department of Endocrinology of the First Affiliated Hospital of Chongqing Medical University. According to the following inclusion and exclusion criteria, 60 diabetic patients with diabetic foot infections (DFIs) with DFO were retrospectively evaluated, thus, resulting in 209 total pathogens. This retrospective review used culture data from patients with DFI who had clinically infected ulcers that were classified as severe on the basis of IWGDF criteria. ${ }^{10}$ All patients with DFO included in the study were required to meet the following conditions: 1) the ulcer lasted more than 2 weeks; 2) the ulcer overlaid a bony prominence; 3) probing of the bone at the ulcer base was positive, or foot ulcers had primary bone exposure; 4) radiological abnormalities suggested active osteomyelitis; 5) the discharge diagnosis was DFO (on the basis of the diagnostic criteria of the 2020 International Working Group on the Diabetic Foot (IWGDF) guidelines ${ }^{10}$ ); 6) each patient was required to have swab specimen, soft tissue, and bone tissue specimen culture results. Patients with Charcot's joint and gangrene were excluded from the study. This study was conducted in accordance with the Declaration of Helsinki and was approved by the Institutional Review Board at the First Affiliated Hospital of Chongqing Medical University (2020-238). The requirement for informed consent was waived because of the anonymous nature of the study and retrospective analysis of the data.

\section{Specimen Collection}

Three cultures were collected from every patient. Swab cultures from the base of the ulcer for each patient were taken at admission (without use of antibacterial drugs). The ulcer wound was flushed with saline solution, and the necrotic tissue and exudates on the surface were removed. Swabs were immediately scrubbed and rolled in a " $Z$ " pattern onto the ulcer surface by nurses and then were placed in sterile test tubes. Soft tissue and bone tissue specimens were collected by plastic surgeons during amputation ( 57 cases) and debridement (three cases) after admission. To obtain the deep soft tissue and bone tissue specimens, the deep soft tissues and bone tissues of the amputated or debrided parts were cut with different sterile instruments and then placed in 
sterilized test tubes. For the collection of bone specimens, if the patient with DFO had a fracture before the operation, the bone tissues on both sides of the broken ends were collected; in the absence of fracture, the bone tissue at the exposed area of the bone or near the proximal end of the ulcer was collected. For soft tissue specimens, the soft tissue at the junction of necrotic and non-necrotic tissue was sharply obtained. Three cultures were sent to the microbiology lab within 1 hour for pathogen culture.

\section{Microbiological Assessment}

Bacterial isolates were identified at the species level with a VITEK 2 Compact automatic microbiological analyzer and the K-B (Kirby-Bauer) method. Each of the strains cultured from the three specimens was identified and assessed for antibiotic susceptibility in accordance with the Clinical and Laboratory Standards Institute protocol. Multi-drug resistant (MDR) strains were assessed according to the standard definitions of multidrug-resistant, extensively drug-resistant, and pandrug-resistant bacteria published by Magiorakos. ${ }^{20}$

\section{Concordance Assessment}

Concordance was defined as the finding of exactly the same bacterial species with identical susceptibility patterns in both specimens. ${ }^{13}$ Kappa value and percentage of concordance were calculated to assess the concordance. Kappa value, 0-0.20, no agreement, 0.21-0.39, minimal agreement, $0.40-0.59$, weak agreement, $0.60-0.79$, moderate agreement, $0.80-0.90$, strong agreement, above 0.90 , almost perfect agreement. ${ }^{21}$

\section{Statistical Analyses}

All data were analyzed by SPSS 22.0 software. The continuous variables were expressed as mean \pm standard deviation $(\mathrm{x} \pm \mathrm{s})$, and the categorical variables were tested by the chisquare test. The statistical significance level was set at $\mathrm{P}<0.05$.

\section{Results}

\section{Characteristics of Patients and Ulcers}

A total of 60 patients with DFO with swab, soft tissue, and bone tissue culture results were included for 45 (75.0\%) men and $15(25.0 \%)$ women, as shown in Table 1 . The patients were between 34 and 87 years of age, with an average age of $62.52 \pm 10.60$ years, and $40(66.7 \%)$ patients were over 60 years of age. The average duration of diabetes was $11.06 \pm$ 8.75 years, the average hospital stays were $32.35 \pm 17.00$ days, and the mean glycated hemoglobin level was $10.25 \% \pm$
Table I Demographical and Clinical Characteristics of 60 Diabetic Patients and Diabetic Foot Ulcers

\begin{tabular}{|c|c|}
\hline Variables & Number (\%) \\
\hline Male & $45(75.0 \%)$ \\
\hline Age & $62.52 \pm 10.60$ \\
\hline The duration of diabetes & $1 \mathrm{I} .06 \pm 8.75$ \\
\hline HbAlc (\%) & $10.25 \pm 2.34$ \\
\hline$\leq 7 \%$ (good control) & $6(10.0 \%)$ \\
\hline Hospital stays & $32.35 \pm 17.00$ \\
\hline \multicolumn{2}{|l|}{ Ulcer aetiology } \\
\hline Purely neuropathic & $38(63.3 \%)$ \\
\hline Purely ischemic & 7 (II.7\%) \\
\hline Neuroischemic & $15(25.0 \%)$ \\
\hline \multicolumn{2}{|l|}{ Duration of the ulcer } \\
\hline 30 days or less & 36 \\
\hline Over 30 days & 24 \\
\hline \multicolumn{2}{|l|}{ Osteomyelitis region } \\
\hline Metatarsals & 28 \\
\hline Hallux & 17 \\
\hline The second phalanx & 12 \\
\hline The third phalanx & 24 \\
\hline The fourth phalanx & 24 \\
\hline The fifth phalanx & 23 \\
\hline Cuneiform & I \\
\hline \multicolumn{2}{|l|}{ Complications } \\
\hline Neuropathy & $56(93.3 \%)$ \\
\hline Lower extremity vascular disease & $37(61.7 \%)$ \\
\hline Nephropathy & $33(55.0 \%)$ \\
\hline Retinopathy & $30(50.0 \%)$ \\
\hline Antibiotics use before admission & 47 (78.3\%) \\
\hline
\end{tabular}

2.34\%. Only six patients had good glycemic control (HbAlc $\leq 7.0 \%$ ). The proportions of purely neuropathic, purely ischemic, and neuroischemic wounds in diabetic patients were $38(63.3 \%), 7(11.7 \%)$ and $15(25.0 \%)$, respectively. A total of 24 patients had a wound duration of more than 30 days before admission. Among the 60 patients included, each had phalanx infections, and 25 (41.6\%) patients had phalanx infections at multiple sites $(\geq 2)$. A total of 37 (61.7\%) patients with DFO had vascular disease, 56 (93.3\%) had peripheral neuropathy, 33 (55.0\%) had renal dysfunction, and $30(50.0 \%)$ had retinopathy. A total of 47 (78.3\%) patients had received antibiotics in one month before admission.

As shown in Figure 1, no definite causes accounted for the largest proportion (30.0\%) in the predisposing factors of DFUs. Among the known predisposing factors, the most common factors were blister rupture and trauma, both 


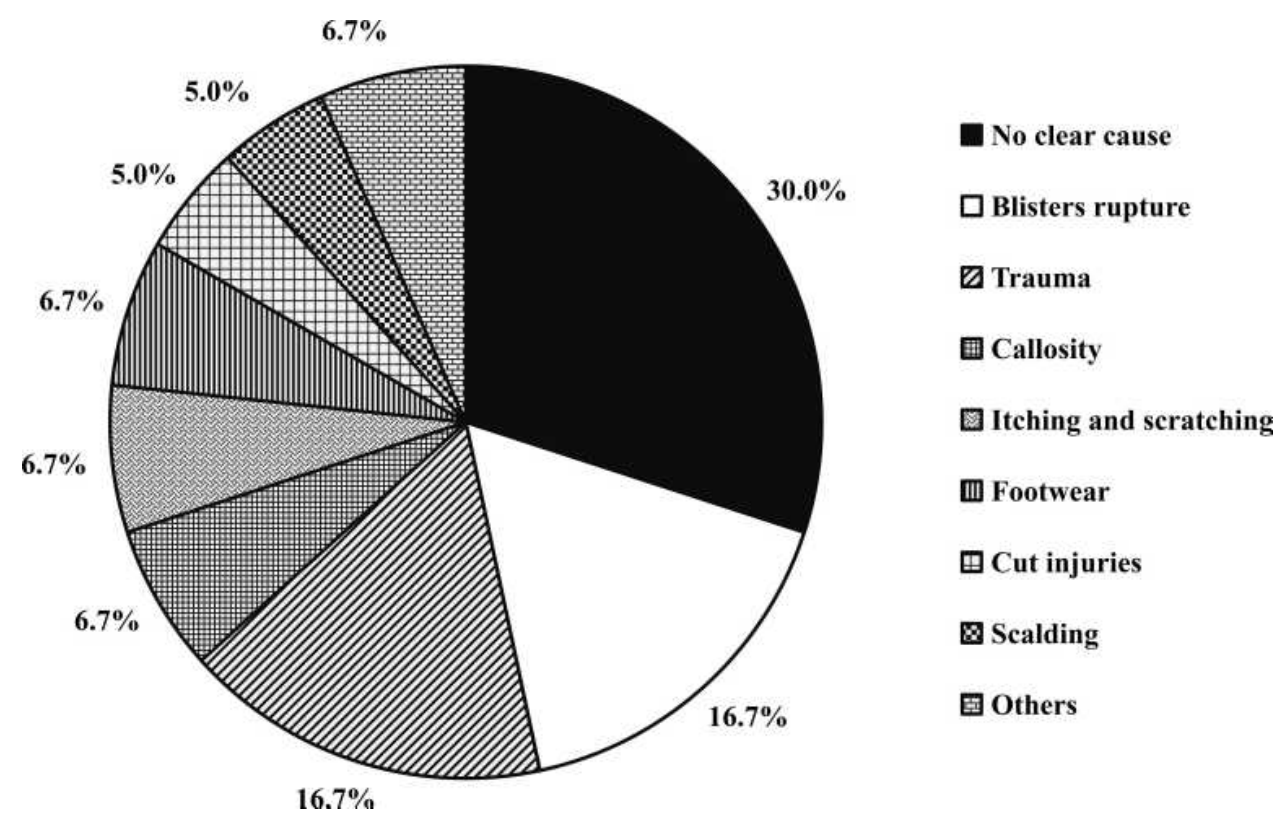

Figure I The component proportion in the predisposing factors of DFUs.

accounting for $16.7 \%$, followed by itching and scratching, callosity, and footwear discomfort, all accounting for 6.7\%; cut injuries, and scalding accounted for $5.0 \%$.

No bacterial culture results were obtained on admission, and the initial use of antibacterial drugs was empirical. The empirical medications were mainly piperacillin, tazobactam, levofloxacin, teicoplanin, vancomycin, imipenem, and meropenem. During the period after admission and before surgery, the anti-infective program was dominated by two antibacterial drugs, accounting for $83.33 \%$ of the drugs used, and a single antibacterial drug accounting for the remaining $16.67 \%$ of drugs administered. Of the two combined antibacterial drug regimens, piperacillin/tazobactam and teicoplanin accounted for $32.00 \%$, and were followed by levofloxacin and teicoplanin $(18.33 \%)$, imipenem-cilastatin sodium and teicoplanin $(10.00 \%)$, piperacillin/tazobactam and vancomycin (6.67\%), and levofloxacin and piperacillin/tazobactam (5.00\%). The single antimicrobial agents were levofloxacin $(50.00 \%)$, piperacillin and tazobactam $(40.00 \%)$, and teicoplanin $(10.00 \%)$. During this period, the average duration of use of these antimicrobials was $11.90 \pm 7.22$ days.

\section{The Distribution of Bacterial Pathogens from Swabs, Soft Tissue, and Bone} Specimens According to Culture Technique As shown in Table 2, 58 (96.7\%) of the patients had positive swab culture results, and 50 patients (83.3\%) had positive soft tissue and bone tissue results. Among the 77 strains of bacteria isolated from the swab specimens, 41 strains (55.8\%) were Gram-positive bacteria, 33 strains $(42.9 \%)$ were Gram-negative bacteria, and three strains $(3.9 \%)$ were fungi. The mean number of isolates per swab specimen was 1.28 (range, 1-3). Among the 67 strains of bacteria isolated from the soft tissue specimens, 35 strains (52.2\%) were Gram-positive bacteria, 27 strains $(42.3 \%)$ were Gram-negative bacteria, and five strains (7.5\%) were fungi. The mean number of isolates per soft tissue culture specimen was 1.12 (range, 1-3). Among the 65 strains of bacteria isolated from the bone specimens, 34 strains $(52.3 \%)$ were Gram-positive bacteria, 26 strains $(40.0 \%)$ were Gram-negative bacteria, and five strains (7.7\%) were fungi. The mean number of isolates per bone specimen was 1.08 (range, 1-3). Our results indicated no significant difference in the composition of pathogens (Gram-positive bacteria, Gram-negative bacteria, and fungi) cultured in the three types of specimens $(P=0.87)$. Staphylococcus aureus was the most common pathogen in various specimens and the most common Gram-positive bacterium. Staphylococcus aureus accounted for 32.6\%, $37.1 \%$, and $29.4 \%$ of Gram-positive bacteria in swabs, soft tissues, and bone tissues, respectively. Enterobacteriaceae was the dominant group of Gramnegative bacteria. The proportion of Enterobacteriaceae in three specimens accounted for $74.2 \%, 85.2 \%$, and $84.6 \%$ of Gram-negative bacteria, respectively. Proteus mirabilis and Morganella morganii were the most common Gram-negative bacteria; Proteus mirabilis accounted 
Table 2 Distribution of Bacterial Pathogens Isolated in Ulcer Swab, Soft Tissue, and Bone Specimen Culture from Patients with DFO

\begin{tabular}{|c|c|c|c|}
\hline Pathogens & Swab Specimens $(n=60)$ & Soft Tissue Specimens $(n=60)$ & Bone Specimens $(n=60)$ \\
\hline Positive specimens & 58 & 50 & 50 \\
\hline No. of isolates & 77 & 67 & 65 \\
\hline Mean no. of isolates per specimen & 1.28 & 1.12 & 1.08 \\
\hline MDR & $20(26.0 \%)$ & $25(37.3 \%)$ & $22(33.8 \%)$ \\
\hline Gram-positive bacteria & 43 & 35 & 34 \\
\hline Staphylococcus aureus & 14 & 13 & 10 \\
\hline Coagulase-negative staphylococci & 3 & 1 & 3 \\
\hline Other Staphylococcus ${ }^{\mathrm{a}}$ & 5 & 3 & 2 \\
\hline MRSA & 2 & 2 & 1 \\
\hline Streptococcus & 11 & 3 & 4 \\
\hline Enterococcus & 6 & 12 & 12 \\
\hline Other Gram-positive bacteria & 4 & 3 & 3 \\
\hline Gram-negative bacteria & 31 & 27 & 26 \\
\hline Escherichia coli & 3 & 3 & 2 \\
\hline Klebsiella pneumoniae & $\mathrm{I}$ & 1 & 2 \\
\hline Enterobacter cloacae & 2 & 2 & 2 \\
\hline Klebsiella aerogenes & 0 & 1 & I \\
\hline Proteusbacillus vulgaris ${ }^{b}$ & 9 & 9 & 9 \\
\hline Citrobacter freundii & 1 & 0 & 0 \\
\hline Serratia marcescens & 2 & 1 & I \\
\hline Morganella morganii & 5 & 6 & 5 \\
\hline Pseudomonas aeruginosa & 4 & 1 & 0 \\
\hline Acinetobacter baumannii & 2 & 1 & 1 \\
\hline Other Gram-negative bacteria & 2 & 2 & 3 \\
\hline Fungus & 3 & 5 & 5 \\
\hline Candida albicans & I & 2 & 2 \\
\hline Candida parapsilosis & I & 1 & 2 \\
\hline Candida tropicalis & I & 1 & 1 \\
\hline Trichosporon asahii & 0 & 1 & 0 \\
\hline
\end{tabular}

Notes: ${ }^{a}$ Other Staphylococcus refers to Staphylococcus epidermidis, Staphylococcus cohnii urealyticum, Staphylococcus haemolyticus, Staphylococcus sciuri, and Staphylococcus lugdunensis. ${ }^{b}$ Proteusbacillus vulgaris refers to Proteus mirabilis and Proteus penteri.

for $19.4 \%, 22.2 \%$, and $23.1 \%$ of the Gram-negative bacteria in swabs, soft tissues, and bone tissues, while the proportion of Morganella morganii in Gram-negative bacteria was $19.4 \%, 22.2 \%$, and $23.1 \%$, respectively.

\section{Concordance Between Bone Tissue Culture versus Swab or Soft Tissue Culture Results}

The pathogens isolated from bone specimens with swabs and soft tissue specimens were identical in a total of 12 cases (20.0\%), and Staphylococcus aureus showed the largest concordance. As shown in Table 3, the culture results from swabs and soft tissue specimens were identical in 15 cases $(25.0 \%)$ and partially identical (with at least one identical bacterium) in 14 cases $(23.3 \%)$. The culture results from swabs and bone tissue specimens were identical in 14 cases $(23.3 \%)$ and partially identical in 13 cases $(21.7 \%)$. The culture results from soft tissue and bone tissue specimens were identical in 46 cases $(76.7 \%)$ and partially identical in five cases $(8.3 \%)$.

The concordance percentage between bone and swab specimens ranged from 0 to $66.67 \%$, with an overall concordance of $23.5 \%$ (Table 4 ). The concordance of the most common Gram-positive bacteria, Staphylococcus aureus and Enterococcus faecalis, was $33.3 \%$ and $20.0 \%$, respectively, and their kappa values were both $<0.40$, thus, indicating poor agreement. The most common Gram-negative bacteria, Proteus mirabilis and Morganella morganii, had a concordance of $50.0 \%$ and $66.7 \%$, respectively, and their kappa values were 0.63 and 0.78 , respectively, thus, indicating moderate agreement. The kappa values of Proteus penneri, Escherichia coli, Serratia marcescens, and Acinetobacter baumannii were all greater than 0.60 , whereas the values for other bacteria were all less than 0.40 . 
Table 3 Concordance Between Bone Tissue versus Swab or Soft Tissue Specimen Cultures from Patients with DFO $(n=60)$

\begin{tabular}{|l|l|l|l|l|l|l|}
\hline \multirow{2}{*}{ Degree } & \multicolumn{4}{|c|}{ Concordance } \\
\cline { 2 - 7 } & \multicolumn{2}{|l|}{ Swab and Soft Tissue } & \multicolumn{2}{l|}{ Swab and Bone } & \multicolumn{2}{l|}{ Soft Tissue and Bone } \\
\cline { 2 - 7 } & No. & Percentage & No. & Percentage & No. & Percentage \\
\hline Identical $^{\mathrm{a}}$ & 15 & $25.0 \%$ & 14 & $23.3 \%$ & 46 & $76.7 \%$ \\
Partially identical $^{\mathrm{b}}$ & 14 & $23.3 \%$ & 13 & $21.7 \%$ & 5 & $8.3 \%$ \\
Different $^{\mathrm{c}}$ & 31 & $51.7 \%$ & 33 & $55.0 \%$ & 9 & $15.0 \%$ \\
\hline
\end{tabular}

Notes: ${ }^{a}$ Identical means that the bacteria detected by the two specimens are exactly the same; ${ }^{b}$ partially identical means that at least one of the bacteria detected in the two specimens is the same but not exactly the same; 'different means that the bacteria detected in the two specimens are completely different.

Table 4 The Concordance of Bacteria Isolated Between Bone Specimen and Ulcer Swab Cultures from Patients with DFO

\begin{tabular}{|c|c|c|c|c|c|}
\hline Pathogen & $\begin{array}{l}\text { From Swab } \\
\text { Specimen Only }\end{array}$ & $\begin{array}{l}\text { From Bone } \\
\text { Specimen Only }\end{array}$ & $\begin{array}{l}\text { From Bone Specimen } \\
\text { and Swab Specimen }\end{array}$ & Concordance $^{\mathrm{a}}(\%)$ & Kappa Value \\
\hline Staphylococcus aureus & 8 & 4 & 6 & $33.3 \%$ & 0.38 \\
\hline Enterococcus faecalis & 3 & 5 & 2 & $20.0 \%$ & 0.26 \\
\hline Proteus mirabilis & 2 & 2 & 4 & $50.0 \%$ & 0.63 \\
\hline Morganella morganii & 1 & 1 & 4 & $66.7 \%$ & 0.78 \\
\hline Other Staphylococcus & 7 & 4 & 1 & $8.3 \%$ & 0.057 \\
\hline Streptococcus & 9 & 2 & 2 & $15.4 \%$ & 0.34 \\
\hline Other Enterococcus & I & 5 & 0 & 0 & -0.029 \\
\hline Escherichia coli & 1 & 0 & 2 & $66.7 \%$ & 0.79 \\
\hline Proteus penneri & 1 & I & 2 & $50.0 \%$ & 0.65 \\
\hline Klebsiella pneumoniae & 1 & 2 & 0 & 0 & -0.023 \\
\hline Enterobacter cloacae & 2 & 2 & 0 & 0 & -0.034 \\
\hline Enterobacter aerogenes & 0 & I & 0 & 0 & 0 \\
\hline Serratia marcescens & 1 & 0 & 1 & $50.0 \%$ & 0.66 \\
\hline Pseudomonas aeruginosa & 4 & 0 & 0 & 0 & 0 \\
\hline Acinetobacter baumannii & 1 & 0 & 1 & $50.0 \%$ & 0.66 \\
\hline Others & 6 & 5 & 1 & $8.3 \%$ & 0.052 \\
\hline Fungus & 2 & 4 & I & $14.3 \%$ & \\
\hline Total & 50 & 38 & 27 & $23.5 \%$ & \\
\hline
\end{tabular}

Note: ${ }^{a}$ Concordance between bone specimen and ulcer swab cultures (\%).

The concordance percentage between bone specimens and tissue specimens ranged from 0 to $100.0 \%$, with an overall concordance of $73.7 \%$ (Table 5). The concordance of the most common Gram-positive bacteria, Staphylococcus aureus and Enterococcus faecalis, was $76.9 \%$ and $75.0 \%$, respectively, and their kappa values were both 0.84 , which denoted strong agreement. The most common Gram-negative bacteria, Proteus mirabilis and Morganella morganii, had concordance of $100.0 \%$ and $83.3 \%$, respectively, and their kappa values were 1.00 and 0.90 , respectively, thus, indicating almost perfect agreement and strong agreement, respectively. Except for Pseudomonas aeruginosa, the kappa values for other bacteria were all greater than 0.60 .

\section{The Distribution of MDR Bacteria}

As shown in Table 2, the number of MDR strains isolated from swab, soft tissue, and bone tissue specimens was 20 (26.0\%), $25(37.3 \%)$, and $22(33.8 \%)$, respectively, and the ratio of MDR bacteria to total pathogens in soft tissue and bone tissue was higher than that in swab specimens, but there was no significant difference among the three tissue specimens $(P=0.32)$.

The MDR bacterial distribution in swab specimens was as follows: $42.9 \%$ of Staphylococcus aureus were MDR bacteria, and only two strains were methicillin-resistant Staphylococcus aureus (MRSA); $83.3 \%$ of Proteus mirabilis were MDR bacteria; $40 \%$ of Morganella morganii were MDR bacteria; all three strains of Escherichia coli were extended-spectrum beta-lactamases (ESBL) producing 
Table 5 The Concordance of Bacteria Isolated Between Bone Specimen and Soft Tissue Specimen Cultures from Patients with DFO

\begin{tabular}{|c|c|c|c|c|c|}
\hline Pathogen & $\begin{array}{l}\text { From Soft Tissue } \\
\text { Specimen Only }\end{array}$ & $\begin{array}{l}\text { From Bone } \\
\text { Specimen } \\
\text { Only }\end{array}$ & $\begin{array}{l}\text { From Bone Specimen } \\
\text { and Soft Tissue Specimen }\end{array}$ & Concordance $^{\mathrm{a}}(\%)$ & Kappa Value \\
\hline Staphylococcus aureus & 3 & 0 & 10 & $76.9 \%$ & 0.84 \\
\hline Enterococcus faecalis & 1 & 1 & 6 & $75.0 \%$ & 0.84 \\
\hline Proteus mirabilis & 0 & 0 & 6 & $100.0 \%$ & 1.00 \\
\hline Morganella morganii & 1 & 0 & 5 & $83.3 \%$ & 0.90 \\
\hline Other Staphylococcus & 1 & 2 & 3 & $50.0 \%$ & 0.73 \\
\hline Streptococcus & 0 & 1 & 3 & $75.0 \%$ & 0.85 \\
\hline Other Enterococcus & 0 & 0 & 5 & $100.0 \%$ & 1.00 \\
\hline Escherichia coli & 1 & 0 & 2 & $66.7 \%$ & 0.79 \\
\hline Proteus penneri & 0 & 0 & 3 & $100.0 \%$ & 1.00 \\
\hline Klebsiella pneumoniae & 0 & 1 & 1 & $50.0 \%$ & 0.66 \\
\hline Enterobacter cloacae & 0 & 0 & 2 & $100.0 \%$ & 1.00 \\
\hline Enterobacter aerogenes & 0 & 0 & 1 & $100.0 \%$ & 1.00 \\
\hline Serratia marcescens & 0 & 0 & 1 & $100.0 \%$ & 1.00 \\
\hline Pseudomonas aeruginosa & 1 & 0 & 0 & 0 & 0 \\
\hline Acinetobacter baumannii & 0 & 0 & 1 & $100.0 \%$ & 1.00 \\
\hline Others & 1 & 2 & 4 & $57.1 \%$ & 0.70 \\
\hline Fungus & 2 & 2 & 3 & $42.9 \%$ & \\
\hline Total & 11 & 9 & 56 & $73.7 \%$ & \\
\hline
\end{tabular}

Note: ${ }^{a}$ Concordance between bone specimen and soft tissue specimen cultures (\%).

bacteria; and a carbapenem-resistant Acinetobacter baumannii isolated from the three specimens with identical susceptibility was insensitive to all tested antibacterial treatments and showed intermediate sensitivity to minocycline.

The MDR bacterial distribution in soft tissue specimens was as follows: $23.1 \%$ of Staphylococcus aureus were MDR bacteria, only two strains were MRSA; $100.0 \%$ of Proteus mirabilis were MDR bacteria; and $66.7 \%$ of Morganella morganii were MDR bacteria. Four ESBL-producing bacteria were isolated, including one strain of Proteus mirabilis and three strains of Escherichia coli. A vancomycin-resistant Enterococcus gallinarum was also isolated.

MDR bacteria in bone specimens were mostly the same as those in soft tissues, with the following differences: $10.0 \%$ of Staphylococcus aureus were MDR bacteria, and $60.0 \%$ of Morganella morganii were MDR bacteria. Three ESBL-producing bacteria were isolated, including one strain of Klebsiella pneumoniae and two strains of Escherichia coli.

\section{Antimicrobial Susceptibility of Pathogens from Bone Specimens}

As shown in Table 6, Staphylococcus aureus was more susceptible to gentamicin, linezolid, vancomycin, tigecycline, rifampicin, and quinupristin/dalfopristin, with a susceptibility of $100 \%$, followed by ciprofloxacin, levofloxacin, moxifloxacin, and sulfamethoxazole, with a susceptibility of $90.0 \%$, and it showed poor susceptibility to erythromycin $(70.0 \%)$ and clindamycin $(70.0 \%)$. Enterococcus faecalis was more susceptible to ampicillin, linezolid, vancomycin, tigecycline, teicoplanin, and penicillin $\mathrm{G}$, with a sensitivity of $100 \%$, followed by levofloxacin (71.4\%), moxifloxacin (85.7\%), and streptomycin $(66.7 \%)$. The susceptibility of Enterococcus faecium to quinupristin/dalfopristin, linezolid, vancomycin, and tigecycline was $100 \%$.

As shown in Table 7, Gram-negative bacteria, all Enterobacteriaceae, were $100 \%$ sensitive to meropenem and imipenem. Piperacillin/tazobactam and ertapenem also showed very strong antimicrobial activity, and all Enterobacteriaceae, except one strain of ESBL-producing Escherichia coli, were sensitive to both antimicrobial agents. Proteus mirabilis was $100 \%$ sensitive to the antibacterial agents aztreonam, ceftazidime, cefotetan, cefoperazone/sulbactam, piperacillin/tazobactam, and carbapenems, followed by amikacin (83.3\%), cefoxitin $(83.3 \%)$, and levofloxacin (66.7\%). Morganella morganii was $100 \%$ sensitive to amikacin, aztreonam, cefoperazone/ sulbactam, cefotetan, ertapenem, cefepime, piperacillin/ 
Table 6 Antimicrobial Susceptibility of Gram-Positive Bacteria from DFO Patients (\%)

\begin{tabular}{|c|c|c|c|c|c|c|c|c|}
\hline Antibiotics & $\begin{array}{l}\text { Staphylococcus } \\
\text { aureus } \\
(n=10)\end{array}$ & $\begin{array}{l}\text { Enterococcus } \\
\text { faecalis } \\
(n=7)\end{array}$ & $\begin{array}{l}\text { Enterococcus } \\
\text { avium } \\
(n=2)\end{array}$ & $\begin{array}{l}\text { Streptococcus } \\
\text { agalactiae } \\
(n=2)\end{array}$ & $\begin{array}{l}\text { Enterococcus } \\
\text { faecium } \\
(n=1)\end{array}$ & $\begin{array}{l}\text { Enterococcus } \\
\text { gallinarum } \\
(n=1)\end{array}$ & $\begin{array}{l}\text { Enterococcus } \\
\text { raffinosus } \\
(n=1)\end{array}$ & $\begin{array}{l}\text { Staphylococcus } \\
\text { cohnii } \\
\text { urealyticum } \\
(\mathrm{n}=\mathrm{I})\end{array}$ \\
\hline Gentamicin & $100.0 \%$ & $42.9 \%$ & $100.0 \%$ & - & $0.0 \%$ & $100.0 \%$ & $100.0 \%$ & $100.0 \%$ \\
\hline Ciprofloxacin & $90.0 \%$ & $25.0 \%$ & $100.0 \%$ & $100.0 \%$ & $0.0 \%$ & - & $100.0 \%$ & $0.0 \%$ \\
\hline Levofloxacin & $90.0 \%$ & $71.4 \%$ & $100.0 \%$ & $100.0 \%$ & $0.0 \%$ & $100.0 \%$ & $100.0 \%$ & $0.0 \%$ \\
\hline Moxifloxacin & $90.0 \%$ & $85.7 \%$ & $100.0 \%$ & $100.0 \%$ & $0.0 \%$ & $100.0 \%$ & $100.0 \%$ & $0.0 \%$ \\
\hline Sulfamethoxazole & $90.0 \%$ & $25.0 \%$ & - & - & - & $0.0 \%$ & - & $100.0 \%$ \\
\hline Ampicillin & $x$ & $100.0 \%$ & $0.0 \%$ & $100.0 \%$ & $0.0 \%$ & $100.0 \%$ & $100.0 \%$ & - \\
\hline Penicillin G & $10.0 \%$ & $100.0 \%$ & $0.0 \%$ & $100.0 \%$ & $0.0 \%$ & $100.0 \%$ & $0.0 \%$ & $0.0 \%$ \\
\hline Oxacillin & $90.0 \%$ & - & - & - & - & - & - & $0.0 \%$ \\
\hline Linezolid & $100.0 \%$ & $100.0 \%$ & $100.0 \%$ & $100.0 \%$ & $100.0 \%$ & $100.0 \%$ & $100.0 \%$ & $100.0 \%$ \\
\hline Quinupristin/Dalfopristin & $100.0 \%$ & $0.0 \%$ & $100.0 \%$ & $100.0 \%$ & $100.0 \%$ & - & $0.0 \%$ & $100.0 \%$ \\
\hline Tetracycline & $50.0 \%$ & $0.0 \%$ & $0.0 \%$ & $0.0 \%$ & $0.0 \%$ & - & $100.0 \%$ & $100.0 \%$ \\
\hline Tigecycline & $100.0 \%$ & $100.0 \%$ & $100.0 \%$ & $100.0 \%$ & $100.0 \%$ & $100.0 \%$ & $100.0 \%$ & $100.0 \%$ \\
\hline Vancomycin & $100.0 \%$ & $100.0 \%$ & $100.0 \%$ & $100.0 \%$ & $100.0 \%$ & $0.0 \%$ & $100.0 \%$ & $100.0 \%$ \\
\hline Clindamycin & $70.0 \%$ & $0.0 \%$ & $0.0 \%$ & $0.0 \%$ & $0.0 \%$ & $0.0 \%$ & $0.0 \%$ & $0.0 \%$ \\
\hline Erythrocin & $70.0 \%$ & $0.0 \%$ & $0.0 \%$ & $50.0 \%$ & $0.0 \%$ & $0.0 \%$ & $100.0 \%$ & $0.0 \%$ \\
\hline Rifampicin & $100.0 \%$ & - & - & - & - & - & - & $100.0 \%$ \\
\hline Streptomycin & - & $66.7 \%$ & $100.0 \%$ & - & $100.0 \%$ & - & $100.0 \%$ & - \\
\hline Daptomycin & - & $100.0 \%$ & - & - & - & - & - & - \\
\hline Teicoplanin & - & $100.0 \%$ & - & - & - & - & - & - \\
\hline
\end{tabular}

Table 7 Antimicrobial Susceptibility of Gram-Negative Bacteria from DFO Patients (\%)

\begin{tabular}{|c|c|c|c|c|c|c|c|c|}
\hline Antibiotics & $\begin{array}{l}\text { Proteus } \\
\text { mirabilis } \\
(n=6)\end{array}$ & $\begin{array}{l}\text { Morganella } \\
\text { morganii } \\
(n=5)\end{array}$ & $\begin{array}{l}\text { Proteus } \\
\text { penneri } \\
(n=3)\end{array}$ & $\begin{array}{l}\text { Escherichia } \\
\text { coli }(n=2)\end{array}$ & $\begin{array}{l}\text { Klebsiella } \\
\text { pneumoniae } \\
(n=2)\end{array}$ & $\begin{array}{l}\text { Enterobacter } \\
\text { cloacae }(n=2)\end{array}$ & $\begin{array}{l}\text { Enterobacter } \\
\text { aerogenes } \\
(n=1)\end{array}$ & $\begin{array}{l}\text { Serratia } \\
\text { marcescens }(n=1)\end{array}$ \\
\hline Ampicillin & $0.0 \%$ & $0.0 \%$ & $0.0 \%$ & $0.0 \%$ & $0.0 \%$ & $0.0 \%$ & $0.0 \%$ & $0.0 \%$ \\
\hline Ampicillin/Sulbactam & $16.7 \%$ & $0.0 \%$ & $33.3 \%$ & $0.0 \%$ & $50.0 \%$ & $0.0 \%$ & $0.0 \%$ & $100.0 \%$ \\
\hline Piperacillin/Tazobactam & $100.0 \%$ & $100.0 \%$ & $100.0 \%$ & $50.0 \%$ & $100.0 \%$ & $100.0 \%$ & $100.0 \%$ & $100.0 \%$ \\
\hline Gentamicin & $0.0 \%$ & $33.3 \%$ & $66.7 \%$ & $0.0 \%$ & $50.0 \%$ & $50.0 \%$ & $100.0 \%$ & - \\
\hline Amikacin & $83.3 \%$ & $100.0 \%$ & $100.0 \%$ & $50.0 \%$ & $100.0 \%$ & $100.0 \%$ & $100.0 \%$ & - \\
\hline Tobramycin & $16.7 \%$ & $33.3 \%$ & $66.7 \%$ & $0.0 \%$ & $50.0 \%$ & $50.0 \%$ & $100.0 \%$ & - \\
\hline Ciprofloxacin & $33.3 \%$ & $80.0 \%$ & $100.0 \%$ & $0.0 \%$ & $50.0 \%$ & $50.0 \%$ & $100.0 \%$ & $100.0 \%$ \\
\hline Levofloxacin & $66.7 \%$ & $80.0 \%$ & $100.0 \%$ & $0.0 \%$ & $100.0 \%$ & $50.0 \%$ & $100.0 \%$ & $100.0 \%$ \\
\hline Cefazolin & $0.0 \%$ & $0.0 \%$ & $0.0 \%$ & $0.0 \%$ & $0.0 \%$ & $0.0 \%$ & $0.0 \%$ & $0.0 \%$ \\
\hline Ceftriaxone & $50.0 \%$ & $80.0 \%$ & $66.7 \%$ & $0.0 \%$ & $50.0 \%$ & $50.0 \%$ & $0.0 \%$ & $100.0 \%$ \\
\hline Ceftazidime & $100.0 \%$ & $80.0 \%$ & $100.0 \%$ & $50.0 \%$ & $100.0 \%$ & $50.0 \%$ & $0.0 \%$ & $100.0 \%$ \\
\hline Cefepime & $100.0 \%$ & $100.0 \%$ & $100.0 \%$ & $50.0 \%$ & $100.0 \%$ & $100.0 \%$ & $0.0 \%$ & $100.0 \%$ \\
\hline Cefotetan & $100.0 \%$ & $100.0 \%$ & $100.0 \%$ & $50.0 \%$ & $50.0 \%$ & $0.0 \%$ & $0.0 \%$ & - \\
\hline Imipenem & $100.0 \%$ & $100.0 \%$ & $100.0 \%$ & $100.0 \%$ & $100.0 \%$ & $100.0 \%$ & $100.0 \%$ & $100.0 \%$ \\
\hline Aztreonam & $100.0 \%$ & $100.0 \%$ & $100.0 \%$ & $0.0 \%$ & $50.0 \%$ & $50.0 \%$ & $0.0 \%$ & $100.0 \%$ \\
\hline Ertapenem & $100.0 \%$ & $100.0 \%$ & $100.0 \%$ & $50.0 \%$ & $100.0 \%$ & $50.0 \%$ & $100.0 \%$ & $100.0 \%$ \\
\hline Meropenem & $100.0 \%$ & $100.0 \%$ & $100.0 \%$ & $100.0 \%$ & $100.0 \%$ & $100.0 \%$ & $100.0 \%$ & $100.0 \%$ \\
\hline Sulfamethoxazole & $0.0 \%$ & $20.0 \%$ & $33.3 \%$ & $0.0 \%$ & $50.0 \%$ & $50.0 \%$ & $100.0 \%$ & $100.0 \%$ \\
\hline Cefoperazone/sulbactam & $100.0 \%$ & $100.0 \%$ & $100.0 \%$ & $50.0 \%$ & $50.0 \%$ & $100.0 \%$ & $0.0 \%$ & $100.0 \%$ \\
\hline Cefoxitin & $83.3 \%$ & $60.0 \%$ & $100.0 \%$ & $50.0 \%$ & $50.0 \%$ & $0.0 \%$ & $0.0 \%$ & $0.0 \%$ \\
\hline Minocycline & $0.0 \%$ & $0.0 \%$ & $0.0 \%$ & $0.0 \%$ & $50.0 \%$ & $50.0 \%$ & $100.0 \%$ & $0.0 \%$ \\
\hline Tigecycline & $100.0 \%$ & $0.0 \%$ & $0.0 \%$ & $100.0 \%$ & $100.0 \%$ & $100.0 \%$ & $100.0 \%$ & $100.0 \%$ \\
\hline Cefuroxime & - & $0.0 \%$ & $0.0 \%$ & - & - & - & - & $0.0 \%$ \\
\hline Cefuroxime axetil & - & $0.0 \%$ & - & - & - & - & - & $0.0 \%$ \\
\hline $\begin{array}{l}\text { Amoxicillin/ clavulanate } \\
\text { potassium }\end{array}$ & - & $0.0 \%$ & - & - & - & - & - & $0.0 \%$ \\
\hline
\end{tabular}


tazobactam, and carbapenems, and relatively sensitive to ceftazidime, ciprofloxacin, ceftriaxone, and levofloxacin, with a susceptibility of $80.0 \%$. Escherichia coli in bone tissue cultures were all EBSL-producing bacteria and had a sensitivity of $100.0 \%$ to imipenem, meropenem, and tigecycline.

\section{Discussion}

DFU infections are a major increasing problem worldwide for people with diabetes and are liable to progress to DFO. ${ }^{22}$ The antibacterial treatment for DFO is extremely complicated, and it requires targeted antimicrobial therapy according to the pathogenic bacteria in infected bone biopsy specimen cultures. However, bone biopsy culture is not easy to perform routinely in clinical practice. Therefore, DFU swabs and deep tissue specimen cultures are used instead of bone biopsy cultures. Our study reports the concordance between bone tissue culture results, and swab and soft tissue culture results. This study also analyzed the antimicrobial susceptibility of bone specimens to provide guidance for the treatment of patients with DFO.

The distribution of pathogenic bacteria cultured in three specimens was dominated by Gram-positive bacteria (more than 50.0\%), in agreement with published results. ${ }^{8,9,13}$ Gram-negative bacteria accounted for more than $40.0 \%$ of the pathogenic bacteria cultured from three specimens. Therefore, the results suggest that empirical antibacterial treatment decisions for treating DFOs should consider both Gram-positive and Gram-negative bacterial infections. Our results also confirmed that Staphylococcus aureus was the most common bacterium isolated from matching swab, soft tissue, and bone tissue cultures. ${ }^{13,16,23}$ The other most common Gram-negative pathogens cultured from three specimens were Proteus mirabilis and Morganella morganii, in contrast to the results reported by Elamurugan, ${ }^{8}$ Malone, ${ }^{9}$ and Senneville. ${ }^{13}$ These findings indicate that dominant DFO pathogens have regional differences. Overall, pathogens were equally represented in cultures of swab specimens, soft tissue, and bone specimens.

The mean number of strains of pathogenic bacteria isolated from the swab and bone specimens was inconsistent with those reported by Senneville ${ }^{13,16}$ and Kessler. ${ }^{24}$ The mean number of strains isolated from the swabs in our study (1.28) was less than those reported in Kessler (2.04), Senneville (2006) (1.58), and Senneville (2009) (2.51). The mean number of strains isolated from the bone samples in our study (1.08) was also less than those reported in
Senneville (2006) (1.54) and Senneville (2009) (1.35). These dissimilarities may be because most patients with DFO (78.3\%) included in our study had been administered antimicrobials before admission, and all patients received antimicrobial therapy before the collection of bone specimens.

In our study, the identical and partially identical proportions between the swab and bone tissue cultures were much lower than those between the soft tissue and bone tissue cultures, and the concordance in the pathogenic bacteria isolated and the kappa value between the soft tissue culture and bone specimen culture results was higher than that between the swab and bone results, thus indicating that bone specimen results were more closely correlated with soft tissue than swab specimen results, and soft tissue culture results have better clinical reference value. These results were consistent with the findings of Elamurugan, ${ }^{8}$ Senneville, ${ }^{13}$ Bozkurt, ${ }^{17}$ and Nelson. ${ }^{18}$ However, the soft tissue culture results could not fully identify pathogenic bacteria from infected bone, and bone specimens remain the only definitive way to determine the causative pathogen in DFO. ${ }^{7-12}$ However, when bone tissue specimens are not available in clinical practice, soft tissue specimens can be considered as a proxy. Although the results between swabs and bone tissue were only $25 \%$ identical, we found that multiple subsequent swab cultures cultivated the pathogenic bacteria from infected bone. In addition, the concordance and kappa value between the swab and bone specimen culture results was much lower for Gram-positive bacteria than Gramnegative bacteria. This result indicates that superficial swabs do not reliably identify bone bacteria in patients with DFO, but the Gram-negative bacteria cultured in the swab specimens more reliably represent bone pathogenic bacteria than Gram-positive bacteria.

The antibacterial effect of antimicrobial treatment for patients with DFO is highly correlated with the resistance of pathogenic bacteria, particularly in MDR infections. In our study, the proportion of MDR bacteria from soft tissue and bone tissue cultured bacteria accounted for more than one-third of the total cultured bacteria, and $28.3 \%$ of patients with DFO had positive MDR results. Such findings were similar to those reported by Heurtier. ${ }^{25}$ Patient factors, such as poor glycemic control, ulcer size greater than $4 \mathrm{~cm}$, frequent hospitalization for the same DFU, the duration of diabetic foot infection, the length of hospital stay, osteomyelitis, and previous administration and duration of antibiotic treatment are significant risk factors for 
infections with MDR. ${ }^{26,27}$ Therefore, patients with the above characteristics can be considered to be at high risk for MDR, and priority should be given to targeted antimicrobial therapy at the beginning of medication. Notably, MDR in Proteus mirabilis (100.0\%), Morganella morganii (60.0\%), and ESBL-producing Escherichia coli (100.0\%) accounted for a relatively high proportion of the Gramnegative bacteria from bone tissue cultured bacteria, and antimicrobial susceptibility testing for these bacteria should be improved.

According to the characteristics of the antimicrobial susceptibility of pathogens from bone specimens in this study, and the domestic and international guidelines for DFIs, ${ }^{10,28}$ empirical antibacterial selections are made to treat DFO infections. However, patients with DFO showed significant bacterial resistance to the initial empirical antibiotics. ${ }^{19}$ MDR occurs in only $11.8 \%$ of Gram-positive bacteria, and $10.0 \%$ of Staphylococcus aureus is MRSA, which comprises only $2.9 \%$ of the total Gram-positive bacteria. Therefore, DFO caused by Gram-positive bacteria can be treated with moxifloxacin, linezolid, vancomycin, and other glycopeptides. Owing to the low clinical efficiency and adverse effects, ${ }^{29,30}$ tigecycline is not recommended by the 2019 IWGDF update for DFO, ${ }^{10}$ although all Gram-positive bacteria were sensitive to tigecycline in this study. In our study, Gram-positive cocci in DFO showed a higher resistance toward clindamycin and ciprofloxacin, and therefore, these agents are not recommended for initial empirical antibacterial treatment alone. The MDR Gram-negative bacteria accounted for $69.2 \%$ of all Gramnegative bacteria, whereas ESBL-producing Enterobacter accounted for only $11.5 \%$ and carbapenem-resistant bacteria accounted for $7.6 \%$. Therefore, except in high-risk patients with DFO with ESBL-producing and carbapenemresistant bacteria, DFO caused by Gram-negative bacteria can be treated with piperacillin/tazobactam, cefoperazone/ sulbactam, ertapenem, imipenem, and meropenem. Although IWGDF guidelines recommend that DFO in highrisk ESBL-producing bacteria can be treated with ertapenem, levofloxacin, moxifloxacin, aminoglycosides, and polymyxin, the resistance of ertapenem and levofloxacin in our study was relatively high. Therefore, imipenem and meropenem were the first choices, but we do not recommend ertapenem and levofloxacin for Gram-negative bacteria in patients with DFO.

There were limitations of the present study. Firstly, up to $78.3 \%$ of DFO patients had used antibacterial drugs when they were admitted, which could lead to a reduction in the number of cultured bacteria; secondly, most of DFO patients were in serious condition when they were admitted to the hospital, which leads to the potential selection bias; thirdly, the swab specimen microbial results were only adopted the first culture positive result and abandoned the subsequent culture positive result, and bone specimens and soft tissues were obtained after receiving antibiotic treatment; fourthly, anaerobic bacteria results were lacking in bacterial drug susceptibility test. In addition, the sample size of this study was a little small since DFO patients had fewer amputations. Therefore, a prospective, multi-center study should be conducted in the future to further explore the concordance between bone tissue culture results with swab specimens and soft tissue specimens in DFO patients for providing more reasonable antibacterial drug choices.

\section{Conclusions}

Our results indicate that soft tissue culture results have more reliable microbiological concordance to identify DFO bacteria than swab culture results, but they cannot fully identify DFO bacteria. Targeted antibiotic therapy for DFO should be based on antimicrobial susceptibility testing in bone tissue specimen cultures. The study may aid in determining initial empirical clinical antibacterial therapies and subsequent targeted antibacterial treatments for patients with DFO.

\section{Acknowledgments}

We are very grateful to the Endocrinology Department and Clinical Laboratory Department for providing the data of DFO.

\section{Author Contributions}

All authors contributed to data analysis, drafting or revising the article, have agreed on the journal to which the article will be submitted, gave final approval of the version to be published, and agree to be accountable for all aspects of the work.

\section{Funding}

This research did not receive any specific grant from funding agencies in the public, commercial, or not-forprofit sectors.

\section{Disclosure}

The authors declare that they have no conflicts of interest. 


\section{References}

1. Lázaro Martínez JL, García Álvarez Y, Tardáguila-García A, García Morales E. Optimal management of diabetic foot osteomyelitis: challenges and solutions. Diabetes Metab Syndr Obes. 2019;12:947-959. doi:10.2147/dmso.s181198

2. Giurato L, Meloni M, Izzo V, Uccioli L. Osteomyelitis in diabetic foot: a comprehensive overview. World J Diabetes. 2017;8 (4):135-142. doi:10.4239/wjd.v8.i4.135

3. Lipsky BA. Osteomyelitis of the foot in diabetic patients. Clin Infect Dis. 1997;25(6):1318-1326. doi:10.1086/516148

4. Aragon-Sanchez J, Lipsky BA. Modern management of diabetic foot osteomyelitis. The when, how and why of conservative approaches. Expert Rev Anti Infect Ther. 2018;16(1):35-50. doi:10.1080/ 14787210.2018.1417037

5. Berendt AR, Peters EJ, Bakker K, et al. Diabetic foot osteomyelitis: a progress report on diagnosis and a systematic review of treatment Diabetes Metab Res Rev. 2008;24(Suppl S1):S145-S161. doi:10.1002/dmrr.836

6. Leekha S, Terrell CL, Edson RS. General principles of antimicrobial therapy. Mayo Clin Proc. 2011;86(2):156-167. doi:10.4065/mcp.2010.0639

7. Peters EJ, Lipsky BA, Berendt AR, et al. A systematic review of the effectiveness of interventions in the management of infection in the diabetic foot. Diabetes Metab Res Rev. 2012;28(Suppl 1):142-162. doi:10.1002/dmrr.2247

8. Elamurugan TP, Jagdish S, Kate V, Chandra Parija S. Role of bone biopsy specimen culture in the management of diabetic foot osteomyelitis Int J Surg. 2011;9(3):214-216. doi:10.1016/j.jjsu.2010.11.011

9. Malone M, Bowling FL, Gannass A, Jude EB, Boulton AJ. Deep wound cultures correlate well with bone biopsy culture in diabetic foot osteomyelitis. Diabetes Metab Res Rev. 2013;29(7):546-550. doi:10.1002/dmrr.2425

10. Lipsky BA, Senneville É, Abbas ZG, et al. Guidelines on the diagnosis and treatment of foot infection in persons with diabetes (IWGDF 2019 update). Diabetes Metab Res Rev. 2020;36(Suppl 1): e3280. doi:10.1002/dmrr.3280

11. Weiner RD, Viselli SJ, Fulkert KA, Accetta P. Histology versus microbiology for accuracy in identification of osteomyelitis in the diabetic foot J Foot Ankle Surg. 2011;50(2):197-200. doi:10.1053/j.jfas.2010.12.001

12. Couturier A, Chabaud A, Desbiez F, et al. Comparison of microbiological results obtained from per-wound bone biopsies versus transcutaneous bone biopsies in diabetic foot osteomyelitis: a prospective cohort study. Eur J Clin Microbiol Infect Dis. 2019;38(7):1287-1291. doi:10.1007/s10096-019-03547-6

13. Senneville E, Melliez H, Beltrand E, et al. Culture of percutaneous bone biopsy specimens for diagnosis of diabetic foot osteomyelitis: concordance with ulcer swab cultures. Clin Infect Dis. 2006;42 (1):57-62. doi:10.1086/498112

14. Ertugrul MB, Baktiroglu S, Salman S, et al. Pathogens isolated from deep soft tissue and bone in patients with diabetic foot infections. J Am Podiatr Med Assoc. 2008;98(4):290-295. doi:10.7547/0980290

15. Lavery LA, Sariaya M, Ashry H, Harkless LB. Microbiology of osteomyelitis in diabetic foot infections. $J$ Foot Ankle Surg. 1995;34(1):61-64. doi:10.1016/s1067-2516(09)80103-8
16. Senneville E, Morant H, Descamps D, et al. Needle puncture and transcutaneous bone biopsy cultures are inconsistent in patients with diabetes and suspected osteomyelitis of the foot. Clin Infect Dis. 2009;48(7):888-893. doi:10.1086/597263

17. Bozkurt F. Comparison of microbiological results of deep tissue biopsy and superficial swab in diabetic foot infections. J Microbiol Infect Dis. 2011;1(3):122-127. doi:10.5799/ahinjs.02.2011.03.0028

18. Nelson A, Wright-Hughes A, Backhouse MR, et al. CODIFI (Concordance in Diabetic Foot Ulcer Infection): a cross-sectional study of wound swab versus tissue sampling in infected diabetic foot ulcers in England. BMJ Open. 2018;8(1):e019437. doi:10.1136/ bmjopen-2017-019437

19. Tardáguila-García A, Lázaro-Martínez JL, Sanz-Corbalán I, García-álvarez Y, Álvaro-afonso FJ, García-Morales E. Correlation between empirical antibiotic therapy and bone culture results in patients with osteomyelitis. Adv Skin Wound Care. 2019;32 (1):41-44. doi:10.1097/01.ASW.0000542527.48815.1f

20. Magiorakos AP, Srinivasan A, Carey RB, et al. Multidrug-resistant, extensively drug-resistant and pandrug-resistant bacteria: an international expert proposal for interim standard definitions for acquired resistance. Clin Microbiol Infect. 2012;18(3):268-281. doi:10.1111/ j.1469-0691.2011.03570.x

21. McHugh ML. Interrater reliability: the kappa statistic. Biochem Med (Zagreb). 2012;22(3):276-282. doi:10.11613/BM.2012.031

22. Lavery LA, Peters EJ, Armstrong DG, Wendel CS, Murdoch DP, Lipsky BA. Risk factors for developing osteomyelitis in patients with diabetic foot wounds. Diabetes Res Clin Pract. 2009;83(3):347-352. doi:10.1016/j.diabres.2008.11.030

23. Mackowiak PA, Jones SR, Smith JW. Diagnostic value of sinus-tract cultures in chronic osteomyelitis. JAMA. 1978;239(26):2772-2775. doi:10.1001/jama.239.26.2772

24. Kessler L, Piemont Y, Ortega F, et al. Comparison of microbiological results of needle puncture vs. superficial swab in infected diabetic foot ulcer with osteomyelitis. Diabet Med. 2006;23(1):99-102. doi:10.1111/j.1464-5491.2005.01764.x

25. Hartemann-Heurtier A, Robert J, Jacqueminet S, et al. Diabetic foot ulcer and multidrug-resistant organisms: risk factors and impact. Diabet Med. 2004;21(7):710-715. doi:10.1111/j.1464-5491.2004.01237.x

26. Zubair M, Malik A, Ahmad J. Clinico-microbiological study and antimicrobial drug resistance profile of diabetic foot infections in North India. Foot (Edinb). 2011;21(1):6-14. doi:10.1016/j. foot.2010.10.003

27. Kandemir O, Akbay E, Sahin E, Milcan A, Gen R. Risk factors for infection of the diabetic foot with multi-antibiotic resistant microorganisms. $J$ Infect. 2007;54(5):439-445. doi:10.1016/j.jinf.2006.08.013

28. Society CD, Diseases CSoI, Regeneration CSfTRa. Chinese guideline on prevention and management of diabetic foot (2019 edition)(III). Chin J Diabetes Mellit. 2019;11(2):92-108.

29. Arda B, Uysal S, Taşbakan M, et al. Use of tigecycline for diabetic foot infections. Wounds. 2017;29(11):297-305.

30. Ingram PR, Rawlins MD, Murray RJ, Roberts JA, Manning L. Tigecycline use in the outpatient parenteral antibiotic therapy setting. Eur J Clin Microbiol Infect Dis. 2016;35(10):1673-1677. doi:10.1007/s10096-016-2709-6

Diabetes, Metabolic Syndrome and Obesity: Targets and Therapy

Dovepress

\section{Publish your work in this journal}

Diabetes, Metabolic Syndrome and Obesity: Targets and Therapy is an international, peer-reviewed open-access journal committed to the rapid publication of the latest laboratory and clinical findings in the fields of diabetes, metabolic syndrome and obesity research. Original research, review, case reports, hypothesis formation, expert opinion and commentaries are all considered for publication. The manuscript management system is completely online and includes a very quick and fair peer-review system, which is all easy to use. Visit http://www.dovepress.com/testimonials.php to read real quotes from published authors. 